\title{
JÜRGEN HABERMAS: RELIGIÃO, DIVERSIDADE CULTURAL E PUBLICIDADE*
}

PAUla MONTERO

\section{RESUMO}

Este trabalho pretende recuperar o modo particular como Jürgen Habermas enfrenta, a partir dos conceitos de publicidade, legitimidade e agir comunicativo, alguns desafios que, em nosso entender, interessam particularmente o pensamento antropológico contemporâneo: o problema da tradução cultural ou da irredutibilidade das diferenças e o problema do lugar da religião no espaço público.

PALAVRAS-CHAVE: Religião; modernidade; espaço público; tradução cultural.

\section{ABSTRACT}

The aim of this essay is to take a reflexive view of the particular way Jürgen Habermas faces some theorethical challenges that, from my point of view, are particulary interesting to anthropological contemporary thought: the cultural translation problem and the presence of religion on the public space.

KEYWORDS: Religion; modernity; public space; cultural translation.

[*] Agradeço a generosa leitura de meus colegas e amigos Marcos Nobre e Adrián Lavalle, cujas sugestões contribuíram para trazer maior clareza ao argumento.

[1] O desafio foi proposto por Flavio Pierucci por ocasião do Encontro da Anpocs de 2008.

[2] Montero, Paula. "Max Weber e os dilemas da secularização: o lugar da religião no mundo contemporâneo". Novos Estudos do Cebrap, n ${ }^{\circ} 65$, mar.2003,pp.34-44; Idem, "Religião, pluralismo eesfera pública no Brasil”. Novos Estudos do Cebrap, $\mathrm{n}^{\circ} 74$, mar. 2006, pp. 47-66.
Ainda que os fenômenos religiosos contemporâneos estejam em processo de profunda mutação, seu estudo tem permanecido confinado às fronteiras disciplinares tradicionais, sobretudo da sociologia e da antropologia, que por terem herdado esse tema como um objeto clássico de sua própria construção se deparam com dificuldades para renovar seus instrumentos de análise e o modo de colocar os problemas nesse campo. Neste trabalho, trata-se de enfrentar o desafio de expandir essas fronteiras a fim de renovar nosso modo de pensar a religião, acionando dispositivos conceituais distintos, oriundos de programas de trabalho que não têm esse campo como um dos principais focos de sua problemática.

Em trabalhos anteriores, procuramos demonstrar como o paradigma weberiano da secularização acabou por engendrar um obstáculo epistêmico à compreensão dos processos que apontavam para a presença e a visibilidade dos fenômenos religiosos na esfera pública² ${ }^{2}$. 
Sugerimos, então, que autores como Jürgen Habermas nos permitiriam pensar o problema sem a necessidade de supor que a emergência da esfera pública fosse o resultado do refluxo dos fenômenos religiosos para o mundo privado e sem que a permanência e mesmo a expansão de atores e discursos religiosos nessa esfera fossem representadas, particularmente em sociedades como as nossas, como um obstáculo à consolidação dos processos democráticos. Trata-se agora de fundamentar conceitualmente o que fora então apresentado apenas como insight e, sobretudo, elaborar as conseqüências dessa abordagem para o fazer antropológico nesse campo. Além disso, na leitura de Habermas que proponho neste ensaio, evidentemente um recorte parcial e interessado, entendo que seu modelo de teoria crítica dialoga com vários problemas com os quais as ciências humanas vêm se debatendo no momento atual, em particular o dilema que opõe, de um lado, a exigência de reconhecimento das particularidades culturais e, de outro, o problema da tradução das diversidades na construção de consensos mais universais 3 . Penso que ao refratar o campo dos estudos religiosos com o prisma dessa interlocução a abordagem antropológica ganha fôlego para produzir um diagnóstico mais abrangente do presente, projeto abandonado pela antropologia pós-moderna atual que, na sua crítica aos clássicos, acabou por renunciar a possibilidade de qualquer teoria social4.

A obra de J. Habermas é, como sabemos, vastíssima e muda ao longo do tempo de registro teórico. No contexto de sua obra de 1962, o conceito de publicidade dizia respeito à reconstrução analítica do processo histórico de gestação do social por meio da emergência de instituições de publicidade burguesas.Segundo Lavalles, na medida em que o autor se afasta de suas considerações genéticas sobre a emergência do social o conceito de publicidade foi depurado de suas particularidades burguesas e passou a designar um princípio abstrato de intermediação entre o Estado e a sociedade. Nessa redefinição, o suposto de um suporte institucional empírico da publicidade é abandonado em prol da idéia da articulação intangível de "fluxos comunicativos", fundamento necessário aos processos de legitimação política que se materializa onde a opinião pública ganha publicidade. Em seu trabalho "Teoria da ação comunicativa", de 1981, a estrutura social da esfera pública passa a ser descrita por Habermas em dois planos — o sistêmico e o mundo da vida - que se acompanham de uma diferenciação de racionalidade social das ações: ações instrumentais, voltadas para a reprodução do sistema (mercado, poder político institucionalizado, Estado ou poder administrativo) e ações comunicativas voltadas para o entendimento (redes periféricas da esfera pública) ${ }^{6}$.

Nossa intenção neste artigo é recuperar o modo particular como Habermas enfrenta, a partir dos conceitos de publicidade, legitimi-
[3] No livro Curso livre de teoria critica, organizado por Marcos Nobre, ele sugere que as contribuições da teoria crítica permitem compreender fenômenos específicos em uma perspectiva mais ampla do que a dos especialistas. Embora não se possa abrir mão do conhecimento especializado é preciso, segundo ele, aprofundar cada vez mais o diálogo entre as disciplinas para propor um diagnóstico acurado e plausível de nosso tempo. Embora não me situe aqui no campo dos estudos da teoria crítica, tomo como inspiração a sugestão do autor de enfrentar o desafio de "encontrar novas relações produtivas entre as disciplinas" (São Paulo: Papirus, 2008,pp.19-20).

[4] A generalização a partir da prática etnográfica é um problema clássico. George Marcus observa que a etnografia, como instrumento de descrição, nunca trabalhou adequadamente com problemas conceituais de ordem mais geral. O mundo dos "eventos mais amplos" aparece sempre, segundo ele, como externos aos pequenos mundos e não são integrados à análise (Marcus, George. "Problemas de la antropologia contemporânea em el mundo moderno". In: Retóricas de la antropologia. Madri: Jucri, 1991, p.165.

[5] Lavalle, Adrián Gurza. "Jürgen Habermas e a virtualização da publicidade". Margem, $\mathrm{n}^{\circ} 16,2002$, pp. 65-89.

[6] Nobre, Marcos e Terra, Ricardo. Direito e democracia: um guia de leitura de Habermas. São Paulo: Malheiros, 2008. 
[7] Emsua obra Direitoe democracia: facticidade e validade, Habermas define o mundo da vida como um sistema de ações e de saberes especializados vinculados à escola, à religião eà família, que tem por função a reprodução do mundo da vida e a validação dos saberes comunicados (Rio de Janeiro: Tempo Brasileiro, 2003, vol. 2, p.92).

[8] Lavalle, op.cit., p.79.

[9] Quando a Esfera Pública se generaliza, isto é, se desliga dos espaços físicos das interações simples, as estruturas comunicacionais comprimem-se, segundo Habermas (op.cit., p. 94), em conteúdos e tomadas de posição desacopladas dos contextos densos dessas interações.

[10] Estamos usando o conceito em seu sentido mais abrangente tal como foi proposto por autores como S. Benhabib ("Models of public space: Hannah Arendt, the liberal tradition and Jürgen Habermas". In: Calhoun, Craig (org.). Habermas and the public sphere. 4 ed. Cambridge, Massachusets Institute of Technology, 1996). Ao criticar a noção habermasiana de "esfera pública burguesa" cunhada no trabalho histórico de 1962, a autora propõe que o volume da esfera pública seja preenchido por um leque diversificado de processos comunicativos que se elaboram em diferentes microcampos. Na leitura de Sérgio Costa (As cores de Ercília: esfera pública, democracia e configurações pósnacionais. Belo Horizonte, Editora da UFMG, 2002, p. 24), Habermas revê seus argumentos sobre o declínio da esfera pública burguesa na reedição de 1990 de seu livro $A m u$ dança estrutural da esfera pública (Rio de Janeiro: Tempo Brasileiro, 2003). Nesse trabalho, Habermas reafirma a importância da esfera pública como órbita da constituição da opinião e da vontade coletiva.

[11] Habermas, The theory of communicative action. Boston: Beacon Press, 1984 [1981]. dade e agir comunicativo, alguns desafios que, em nosso entender, interessam particularmente o pensamento antropológico contemporâneo: o problema da tradução cultural ou da irredutibilidade das diferenças e o problema do lugar da religião no espaço público. Para tratar essas questões, vamos privilegiar a dimensão do "mundo da vida"7, esfera das interações na qual as ações comunicativas se voltam para a apropriação do existente e para a produção de sentidos que escapam ao controle administrativo ${ }^{8}$. Neste nível não cabe, talvez, o uso da noção de Esfera Pública tal como foi elaborada por Habermas em sua obra de 1962 que, então, supunha o suporte de uma institucionalidade propriamente política e procedimentos de argumentaçãos. Ainda assim, pretendemos recuperar a noção de "publicidade" elaborada nesta primeira fase de sua obra, não tanto para reaver sua dimensão histórica, mas para enfatizar a permanência, em sociedades como as nossas, de espaços de interação dialógicas atrelados a bases institucionais mais ou menos periféricas e relativamente autônomas em face do Estado e das instituições político-administrativas que, ao dar suporte aos discursos religiosos, modulam o mundo da vida e contribuem para moldar a opinião pública ${ }^{10}$.

\section{A TRADUÇÃO CULTURAL DA DIFERENÇA COMO PROBLEMA ANTROPOLÓGICO}

Em seu trabalho de 1981, The theory of communicative action ${ }^{11}$, Habermas dedicou um longo capítulo à definição das características do pensamento mítico para demonstrar por que,em suas atitudes básicas em relação ao mundo, esse tipo de conhecimento não permite ações racionalmente orientadas, isto é, ações auto-reflexivas voltadas para a discussão das regras da própria comunicação. Apoiando-se em autores clássicos da antropologia, tais como Lévy-Bruhl, E. Pritchard, Lévi-Strauss e M. Godelier, o autor argumenta que o pensar analógico que sustenta esse tipo de conhecimento projeta em um mesmo nível coisas e pessoas, objetos e agentes, ação comunicativa e ação teleológica, intervenção instrumental e relações interpessoais. Nesse sentido, as pretensões de validade que no pensamento moderno foram diferenciadas - a saber: a observação compartilhada de que um estado de coisas existe como algo objetivo (verdade da proposição), o pressuposto de uma comunicabilidade das normas compartilhadas (correção da norma) e a adequação ao mundo subjetivo (sinceridade das expressões) - no pensamento mítico constituem uma unidade. Desse modo, em contraste com os pressupostos modernos de compreensão do mundo, as sociedades pautadas por esse tipo de pensamento não são orientadas para o dissenso e a discussão das normas.

Ao postular que a racionalidade assim compreendida não constitui um fenômeno universal, Habermas retoma uma questão clássica 
da antropologia: a comensurabilidade das civilizações, questão esta que desde 1960 esteve no centro da discussão entre cientistas sociais efilósofos. Não vamos retomar todos os argumentos a partir dos quais o autor se posiciona nesse debate. Mas para os propósitos que aqui nos interessam - o de repensar a irredutibilidade das diferenças no escopo das sociedades modernas - , chamaremos atenção para três questões fundamentais levantadas pelo autor nesse percurso. A primeira diz respeito ao plano contextual e histórico: o autor observa que o interesse pelas generalizações teóricas e a abertura para a crítica é uma exigência cognitiva que se impõe, para as sociedades tradicionais, apenas quando elas são obrigadas a entrar em interação com outras visões de mundo. A segunda refere-se ao próprio fazer antropológico: quando o antropólogo está diante de uma visão de mundo que lhe parece irracional (ou não fundada no seu próprio modo de ver o mundo), ele não tem outra escolha a não ser tentar elucidar o seu sentido. Para Habermas isto não significa, no entanto, que seja preciso supor a existência de "racionalidades alternativas". Por fim, no plano de sua teoria da modernidade/racionalidade, o autor pondera que o pensamento moderno não pode ser descrito apenas a partir das propriedades formais da mentalidade científica - a finalidade primordial das visões de mundo não é apenas a de construir um instrumental cognitivo sobre a realidade externa, mas também produzir entendimento a respeito do mundo social comum e das experiências subjetivas. Assim, seria preciso incluir diferentes aspectos de validade das proposições quer se trate de discurso teórico, prático, estético, terapêutico etc., uma vez que as visões de mundo não constituem apenas processos cognitivos, mas também funcionam para estabilizar identidades ainda que, nas sociedades contemporâneas, o façam de maneira cada vez mais formal e aberta à revisão.

As questões que privilegiamos nesse debate permitem desenhar, a nosso ver, um programa de trabalho para pensar a questão da comunicabilidade das diferenças e o modo de produzir consensos entre os diversos modos de ver o mundo no âmbito das sociedades contemporâneas. Começando pela primeira observação apontada acima, ressaltamos que, nas condições atuais de pesquisa, o antropólogo só pode se debruçar sobre visões de mundo "míticas" que já estão em processo mais ou menos longo de interação com visões de mundo reflexivas. Desse modo, a exigência de reflexibilidade e de abertura para a revisão faz obrigatoriamente parte de seu modo de apresentar a validade de suas proposições.

Isso leva à segunda observação. Ao apresentar como problema a elucidação do sentido de uma visão de mundo percebida como distinta, a antropologia se colocou o problema de como traduzir o "ponto de vista" do nativo. A crítica pós-moderna reposicionou essa questão em 
[12] Marcus, G. e Clifford, J. Writing culture. Berkeley: University of California Press, 1986, p. 168.

[13] Marcus, G. e Fischer, M.Anthropology as cultural critique: an experimental moment in the history of social sciences. Chicago: University of Chicago Press,1986, p. 29. termos contemporâneos, lembrando que a supressão do olhar distanciado - condição histórica para a construção das diferenças como alteridade - obrigou a etnografia a mudar suas convenções de descrição das diferenças. George Marcus e J. Clifford chamaram atenção para o fato de que, diferentemente do que ocorria no século XIX ou nos anos de 1920, a figura do "primitivo" não é mais, contemporaneamente, uma força de atração. Apesar de que

[... o desafio para descobrir e representar a diversidade cultural ainda éforte, observam eles, fazê-lo em termos de culturas espaço-temporais a serem preservadas parece démodé. Ao contrário, as forças da diferença mais fortes estão agora definidas no campo cultural capitalista [...]. Samoa ou os trobriandeses não são mais percebidos como uma alternativa convincente de modo de ser ${ }^{12}$.

Seria preciso, pois, romper com o tropo da "comunidade autocontida" da etnografia realista de autores como Malinowski:em vez de fazer uma exegese das "culturas ou cosmologias" que tira as categorias nativas de seus contextos de discurso e as reinsere no modelo analítico do etnógrafo para que elas se tornem compreensíveis através dessa "tradução", o autor sugere uma apropriação dialógica dos conceitos nativos e antropológicos. A compreensão transcultural ocorre, segundo ele, "por aproximação e diálogo". Tratar-se-ia de uma correção mútua do entendimento por ambas as partes até o consenso ${ }^{13}$ ). Nesse processo, a relação observador/observado introduziria necessariamente a reflexibilidade em outras culturas: os povos clássicos assimilam e apropriam-se do conhecimento antropológico produzido sobre eles.

Apesar do avanço teórico presente nessa proposição, ao levar em conta que não se pode representar uma cultura "outra" sem supor que a reflexibilidade já foi introduzida no próprio processo de representação, ela ainda situa o processo de construção de sentido na relação do antropólogo com seu objeto, produzindo uma confusão entre o plano da autocompreensão dos sujeitos e o plano do objeto da antropologia. A abordagem habermasiana permite-nos sugerir uma etnografia dos próprios processos de negociação dos sentidos. Parece-nos que os trabalhos etnográficos, tanto na vertente fenomenológica - que dão atenção ao modo como os nativos "vêem o mundo" - , quanto na vertente hermenêutica - que se pergunta como os nativos "decifram seus textos" - , permanecem presos ao postulado do "ponto de vista nativo", obrigando um esforço de reconstrução "não contaminada" pela reflexibilidade das significações do outro ou de um modelo capaz de objetivar o outro enquanto outro anterior à relação de conhecimento que o apreende. Não é mais plausível, a nosso ver, colocar em époché o processo da interação, de modo a pro- 
duzir um modelo da alteridade irredutível; sugerimos, ao contrário, que é analiticamente mais produtivo trazer para o centro do problema o modo pelo qual as diferentes visões de mundo entram em comunicação e disputam os sentidos a respeito do mundo social e subjetivo. Uma etnografia dos processos de reflexibilidade e disputa sobre as diferenças permitiria compreender os consensos provisórios que dão certa estabilidade a distinções particulares produzidas em determinados contextos, entre o nós e o eles.

Quanto àúltima observação, a saber, para Habermas a racionalidadevoltada para o entendimento abrange proposições deordem prática, estética, terapêutica etc., ela sugere que a linguagem religiosa pode ser incluída em seu modelo discursivo de racionalização em dois níveis. Essa linguagem imbricada nos modos de expressão característicos do mundo da vida está também, em grande parte, voltada para a produção do entendimento a respeito do mundo social comum e a respeito das experiências subjetivas com relação às diferenças e às identidades. Assim, embora Habermas não tenha explorado esta possibilidade, seu insight permite ancorar a abordagem do problema clássico da produção de sentidos no plano das interações que se dão no âmbito da linguagem. Em nossa maneira de ver, o conceito do "agir comunicativo" de Habermas possibilita deslocaro problema da compreensão "do ponto de vista do nativo", do plano dos sentidos internos da cultura que postula o consenso como uma disposição ética do antropólogo, do plano da tradução como representação "autêntica" da experiência longínqua para o plano das interações discursivas que produzem as diferenças entre o "nós" e o "eles". Trata-se, pois, de analisar o jogo da reflexibilidadee a maneira pela qual cada um expõe discursivamente as próprias imagens de mundo em contraoposição às imagens alheias, de modo a jogar as cartas das pretensões de validade das interpretações de mundo tornada visíveis e pensáveis pelos discursos.

Tomando para si a interpretação que Peter Winch faz da teoria de Wittgenstein sobre a linguagem, Habermas propõe que a comparação das imagens de mundo nas interações leve em consideração não apenas o conhecimento do mundo e o controle da natureza, mas também o seu potencial de fundamentação de sentido sobre a ordem do mundo. As interações discursivas não têm a ver, assim, com a comparação abstrata de valores para encontrar sua equivalência e/ou tradução de um repertório para outro. Trata-se, ao contrário, de compreender como, mediante ações discursivas, se produzem consensos sobre normas de ação que terão validade prescritiva. Esse deslocamento permite superar o problema teórico, sempre colocado na descrição etnográfica, de como chegar à fonte última da distinção entre as culturas, operação sem a qual pareceria impossível compreendê-las. A pergunta que as condições etnográficas contemporâneas impõe e que, a nosso ver, a 
teoria habermasiana ajuda a formular de maneira nova é a dos procedimentos lingüísticos que levam a produção de acordos sobre quais são e o que significam as diferenças. Esse modo de ordenar a questão das diferenças no plano da linguagem revigora nossa imaginação antropológica, de modo a pensar, no âmbito de nossa própria sociedade, o problema das especificidades culturais em termos de sua disputa pela visibilidade no espaço público.

\section{RELIGIão, PUBLICIDADE E AGIR COMUNICATIVO}

As condições atuais de coexistência necessária de diferenças culturais tornaram mais aguda uma das principais características das sociedades modernas: a imposição da convivência em um mesmo espaço político de uma pluralidade de concepções de mundo e formas de vida ${ }^{14}$. Até muito recentemente a igreja Católica foi capaz de produzir, nas sociedades de matriz histórica européia, os nexos simbólicos e institucionais mediadores dessas diversas eticidades. Segundo Nobre, na teoria política que Habermas elabora a partir de Direito e democracia,é o direito que preenche hojeessa função: trata-se de uma instituição mediadora capaz de transformar o poder comunicativo que circula na base da sociedade em poder administrativo. Embora o direito tenha passado a ocupar essa função mediadora que por muitos séculos fora no ocidente prerrogativa da religião cristã, parece-nos que as religiões ainda são parte importante das dinâmicas simbólicas que, em sociedades como as nossas, modulam a experiência vivida e os processos de socialização. $\mathrm{O}$ foco de nosso interesse não está, no entanto, em tomar o conceito de publicidade para analisar os processos de intermediação das religiões entre a sociedade e o Estado, mas, sim, em mobilizá-lo analiticamente para compreender a maneira pela qual os sentidos presentes e virtuais a respeito das diferenças que circulam como possibilidades no horizonte do mundo da vida se estabilizam, ainda que provisoriamente, pela mediação de categorias religiosas em uma configuração de identidades que ganham visibilidade e expressão pública.

Para que possamos compreender mais claramente o lugar da religião no modelo habermasiano, procuraremos detalhar as distinções $e$ as relações, às vezes pouco explicitadas em sua obra, entre as noções de publicidade, esfera publica política e mundo da vida. Sérgio Costa sugere que as forças das interações comunicativas voltadas para o entendimento não migram imediatamente para o plano político institucional ${ }^{15}$. Quanto às interações do mundo da vida, nem todas ganham publicidade. A idéia de "instituições de publicidade", presente na obra de 1962, e posteriormente dissipada pela sua metamorfose em uma noção mais abstrata de publicidade como fluxos 
comunicativos, ainda nos parece útil para compreender antropologicamente as dinâmicas das práticas de publicidade ${ }^{16}$. Nesse espaço garantido por instituições não estatais, instituições periféricas tais como as igrejas e outras agremiações religiosas, em sua dupla dimensão pública e privada, moldam em seus próprios termos algumas das pretensões de validade oriundas das interações do mundo da vida relativas à estabilização das identidades.

Vejamos agora se a reflexão de Habermas sobre os fenômenos religiosos possibilita esse tipo de apropriação antropológica.

Para além de seu esforço teórico de fôlego em 1981, no qual Habermas critica o conceito de racionalidade weberiana como resultante do processo de desencantamento do mundo, o tema da religião não recebeu, da parte do autor, um tratamento específico até 2006. Nesse ano, ele publica no European Journal of Philosophy, o artigo "Religião e esfera pública".

Habermas começa a pensar o problema da religião de maneira mais explícita no contexto do desafio político dos fundamentalismos religiosos e dos conflitos étnicos da Europa dos anos de 1990. Essa conjuntura suscita no autor a necessidade de retomar seu debate com o modelo weberiano, que associa modernização à secularização do mundo. Surpreende em particular o autor a revitalização política da religião nos Estados Unidos, onde o dinamismo da modernização foi bemsucedido. Desse modo, ele sugere que a associação imediata que Weber ajudou a construir entre religião e tradicionalismo deve ser revista.

Em seu trabalho de 2006, Habermas reconhece que, ao contrário do que a teoria da weberiana da secularização postulara, a história da modernização não coincidiu sempre com a história da secularização. Nos Estados Unidos, a introdução da liberdade religiosa não significou a vitória da laicidade, mas, sim, a introdução da idéia de tolerância para com as minorias religiosas, posto que, historicamente, se tratava de garantir aos colonos que fugiam das guerras religiosas da Europa a liberdade de continuar a exercer suas próprias religiões ${ }^{17}$.

Além disso, o autor também reconhece que, no presente, Igrejas e comunidades religiosas continuam a preencher em muitas partes do mundo, até mesmo por solicitação do Estado, funções importantes para a estabilização de uma cultura pública secular ${ }^{18}$. Não há como pretender, pois, que os fenômenos religiosos possam ser compreendidos como relíquias do passado e a liberdade religiosa uma versão cultural da conservação das espécies em risco de extinção. Mantido esse ponto de vista, as religiões, segundo ele, não teriam nenhuma justificativa intrínseca para existirem e não seriam capazes de resistir à pressão para a modernização.

Como resolver, então, a aporia colocada pelo modelo weberiano no qual a religião exigiria de seus fiéis o "sacrifício da inteligência",
[16] Segundo Lavalle, a idéia de publicidade em Habermas evoluiu de seu sentido genético de construção histórica da autonomia material e moral da burguesia para um conceito mais abstrato: estatuto do que é público. A publicidade burguesa como fenômeno histórico teria permitido a constituição da noção de esfera de publicidade, espaço para a formação de consensos que se expressam na opinião pública. Mais recentemente, segundo o autor, Habermas redefine o conceito publicidade em termos de fluxos comunicativos espontâneos, abandonando a necessidade de suportes institucionais (Lavalle, op. cit., p. 69).

[17] Habermas. "Religion and the public sphere". European Journal of Philosophy, vol.V, ${ }^{\circ}{ }_{14}, 2006$, p. 33 .

[18] Ibidem, p. 6. 
[19] Ibidem, p. 15 .

[20] Habermas, The theory of communication action, op. cit.

[21] Idem, "Religion and the public sphere", op. cit. p. 16.

[22] Araújo, Luiz Bernardo Leite. Religião e modernidade em Habermas. São Paulo: Loyola, 1996, p.127. impedindo-os de assumir nas res publica os procedimentos do debate democrático?

A posição de Habermas nessa disputa nos parece bastante interessante. Ele defende que as religiões podem ter contribuições cognitivas para a esfera política ${ }^{19}$. No entanto, constrói sua argumentação no contexto de uma sociedade pós-seculare pós-metafísica que não postula a finitude da razão confrontando, pois, o posicionamento epistemológico da sociologia weberiana e da filosofia da consciência. Nesse sentido, sua teoria do agir comunicativo é chave.

Como já o fizera em sua releitura de Weber ${ }^{20}$, Habermas reconhece a importância histórica das doutrinas religiosas na genealogia de nossa idéia de razão. Mas, ao lado disso, rejeita uma concepção cientificista limitada de razão que exclui e desvaloriza todas as categorias e afirmações que não podem ser reduzidas a observações controladas, posições nomológicas ou explicações causais. Assim, o autor alarga seu conceito de razão de modo a incorporar os julgamentos morais, legais e religiosos ${ }^{21}$. Nessa abertura reside, a nosso ver, sua contribuição para o estudo de fenômenos que interessam à antropologia da religião. Em seu conceito multidimensional de razão, ela não constitui uma posição fixa em sua referência com o mundo objetivo. Os julgamentos morais e religiosos disputam com outros a formulação sobre o modo de ser do mundo. Com fina sensibilidade antropológica Habermas reconhece que todo conhecimento depende do modo como o homem se interpreta e como interpreta sua posição diante da natureza. Mas ao contrário do pensamento antropológico que procurou alargar o conceito de razão tornando-o relativo, Habermas entende que a razão não pode ser assim considerada porque não diz respeito a conteúdos ou a formatos de conhecimento, mas sim a formas de procedimento. Os procedimentos da racionalidade são, segundo o autor, de natureza discursiva. Trata-se de ressaltar a atitude performativa adotada pelos participantes de qualquer interação mediada pela linguagem: a performance lingüística é instrumento para a emergência de consensos em torno das regras e das convenções que definem a unidade e o significado do mundo. Elas estão, portanto, permanentemente sujeitas à controvérsia. A "razão comunicativa" é portanto dialógica, não no sentido da relação sujeito/objeto tal como ela é entendida pela antropologia pós-moderna, mas porque os falantes levantam pretensões de validade em relação às coisas existentes, aos vínculos interpessoais $e$ às vivências. Essas pretensões só serão aceitas se forem capazes de produzir um consenso com relação à sua própria validade.

Assim, embora o autor leve em consideração a razão instrumental de Weber orientada para o sucesso, o foco de sua análise é a razão orientada para a interação e para o entendimento ${ }^{22}$. Para formular esta dimensão da ação que ele chama de "agir comunicativo", utili- 
za a distinção dos atos de fala de Austin: atos perlocutórios - que exercem um efeito sobre o ouvinte (para amedrontar, persuadir) dependendo para isto, fundamentalmente, da situação da enunciação aqueles que causam algo no mundo - ; atos ilocutórios - que realizam a ação denominada pelo verbo (o falante realiza algo ao dizer, sendo que o essencial é o significado do enunciado) -; atos locutórios - o falante diz algo.

Para Habermas, no agir comunicativo os agentes perseguem com seus atos de fala fins ilocutórios, embora ele reconheça, segundo Araújo, a presença de estratégias perlocutórias nas interações mediadas lingüisticamente ${ }^{23}$. George Herbert Mead fornece a Habermas uma [23] Ibidem, p. 127. teoria da ação baseada em um modelo de interação, retrabalhado pelo autor em termos de comunicação. Além disso, ao sublinhar o caráter simbólico da ação social em que ela deixa de ser tomada como mera tradução mecânica das regras e passa a ser compreendida como aberta e submetida ao contínuo reconhecimento, Mead lhe aponta também um caminho para superar uma perspectiva monológica da teoria da ação. Nele encontra as raízes de um agir comunicativo pré-lingüístico, ligado à constituição do mundo dos objetos observáveis e à afirmação das identidades 24 .

Autores como Pierre Bourdieu também foram buscar em Mead e no interacionismo simbólico inspiração para integrar uma teoria do simbólico a uma teoria da ação concebida de modo menos mecânico ou como subproduto da estrutura. No entanto, embora Bourdieu também leve em conta a linguagem para pensar a lógica das práticas, ele o faz na chave de leitura durkheiminiana da "representação", que privilegia as categorias de conhecimento e suas funções lógicas. As forças sociais de representação constituem para Bourdieu uma luta pela classificação do mundo social, luta pelo monopólio de fazer ver e reconhecer legitimamente a existência de divisões sociais. Nesse sentido para ele, a representação, em grande parte, constrói o mundo que ela representa.

Como para Bourdieu, para quem o mundo simbólico torna possível o consenso sobre o mundo social posto que integração lógica e moral aparecem associadas, a teoria da solidariedade de Durkheim oferece a Habermas uma teoria social que relaciona integração social e integração do sistema. Durkheim vê no conceito de "obrigação" um dos traços constitutivos da norma moral25. Mas a sanção é apenas um aspecto da aceitação da norma; é preciso levar em conta também o desejo de obedecer. Estas duas características do fato moral — o desejo e o dever - levam Durkheim a propor uma analogia entre esfera da moralidade e a do sagrado. Desse modo, a antropologia durkeiminiana oferece a Habermas um modelo para integrar à sua análise as ações rituais. Estas se movem em um nível pré-lingüístico: expressam um consenso 
[26] Para Habermas a história das sociedades move-se em direção à demanda crescente de legitimação lingüisticamente organizada. As sociedades arcaicas interpretam-se pelo mito e fixam sua validade normativa a partir de si mesmas; as sociedades tradicionais interpretam-se pela narrativa teológica e avalidade normativa depende de leis garantidas pelo poder sagrado de um chefe político; nas sociedades modernas a argumentação substitui a doxa: "a cultura é investida da tarefa de justificar porque a ordem política existente merece ser reconhecida". Ver Habermas. Théorie de l'agir communicationnel. Paris: Fayard, 1987, pp. 35 e 206.

[27] Araújo,op.cit.,pp.157-58.

[28] Giddens, A. Política, sociologia e teoria social. São Paulo: Editora da Unesp, 1997, p. 288.

[29] Habermas distingue nas sociedades complexas duas esferas opostas e em permanente tensão: a do mundo da vida e a do sistema. Quanto mais complexos os sistemas sociais mais periféricos se tornam os mundos da vida. No entanto, todo acréscimo de complexificação no primeiro plano só ganha força se acompanhado de um processo equivalente no segundo (Araújo, op.cit., p.165).

[30] Schutz toma o termo da obra de Husserl. Em 1940 ele declara que a fenomenologia é a "filosofia do mundo da vida". Na leitura que Helmut R. Wagner faz de sua obra, Schultz devotou parte considerável de seu esforço interpretativo à exploração das estruturas cognitivas e das experiências do mundo da vida. Seu objetivo era reinterpretar o mundo do trabalho, não do ponto de vista dos arranjos institucionais ou do sistema econômico, mas sim sob o ângulo da intenção humana, da cognição e do esforço subjetivo na cooperação (Wagner, Helmut R.Alfred Schütz: an intellectual biography. Chicago: University of Chicago Press, 1983, pp. 289-290).

[31] Ibidem, p. 291. normativo atualizado regularmente. No entanto, o consenso normativo garantido pelo rito e mediado pelo símbolo constitui o "núcleo arcaico" da solidariedade coletiva. Em contextos modernos de ação os símbolos religiosos não são mais capazes por si só de expressar o coletivo. $O$ consenso normativo que era garantido pelo rito, ancorado nos símbolos religiosos e interpretado pela "semântica do sagrado" se dissolve e dá lugar à "verbalização do sagrado" 26 , isto é, estruturas de ação orientadas para a intercompreensão. A autoridade do sagrado é, assim, gradualmente substituída pela autoridade do consenso ${ }^{27}$.

Com base nesta idéia de "verbalização do sagrado" Habermas permite deslocar o problema do simbólico do campo da representação para o campo da ação como argumentação: compreender o outro não depende, como na tradição compreensiva de Dilthey e Weber, da possibilidade de (re)presentar os pensamentos e os sentimentos daqueles cuja conduta ou pensamento deve ser compreendida ou colocar-se do ponto de vista dos atores ${ }^{28}$, mas sim entrar em diálogo com o outro. A compreensão não é tida, assim, como um método de investigação particular, modo como a antropologia interpretativa absorveu o suposto fenomenológico da possibilidade de (re)experimentação do exótico, mas o modo como a própria vida é constituída. Nesse plano não-sistêmico a ação desenvolve-se no domínio do "mundo da vida", da experiência vivida, cuja função simbólica é coordenada para o consenso. O "mundo vivido" é o horizonte a partir do qual se dão os processos comunicativos e a interação: ele delimita a situação da ação, mas permanece inacessível à tematização ${ }^{29}$.

Embora a noção de "mundo vivido" esteja ainda pouco sistematizada na obra de Habermas, ela foi desenvolvida com base na tradição fenomenológica de Edmund Husserl e Alfred Schütz $3^{\circ}$. Para este último, ele constitui a esfera da experiência cotidiana e do trabalho, em que prevalece o uso de uma "razão prática" subjetiva e situacional, pois visa mais à utilidade do que à verdade ${ }^{31}$. Nesse sentido, o "mundo vivido" em Schütz pode ser compreendido como um contexto de convicções não formuladas explicitamente e que serve como pano de fundo para a interação social. Habermas toma para si essa noção de Schütz enfatizando sua função na intercomunicação: esse contexto pré-reflexivo oferece uma reserva de convicções não objetivadas mas lingüisticamente estruturada, à qual os atores recorrem para sustentar suas interpretações. É a partir desse saber implícito e não problematizável que, segundo Habermas, os falantes e os ouvintes podem pretender reciprocamente que seus enunciados coincidam com o mundo (objetivo, social e subjetivo, criticar e fundamentar suas pretensões de validade, resolver suas dissensões e chegar a um acordo No entanto, tendo em vista suas características próprias já assentadas na tradição fenomenológica clássica - a saber sua imediatez, sua força totaliza- 
dora e seu holismo - não há como produzir a seu respeito um olhar externo e objetivador ${ }^{2}$.

Ao tomar emprestada a noção de "mundo vivido" da sociologia schütziana, Habermas parece muitas vezes associá-la ao conceito de "cultura como tradição" próprio às escolas fenomenológicas. Atento, no entanto, ao essencialismo inerente a essa posição o autor procura corrigir a redução culturalista desse conceito sugerindo que as tradições são apenas um dos três componentes do mundo vivido. Ao seu lado estão também as instituições que asseguram a solidariedade e as competências da personalidade. Esses três níveis do "mundo da vida" não devem ser, pois, tratados como fatos sociais, mas, ao contrário, são teoricamente formulados em termos da interação comunicativa:

[...] chamo cultura a provisão de saber de onde os participantes da comunicação extraem interpretações ao se entenderem sobre algo no mundo. Chamo sociedade aos ordenamentos legítimos pelos quais os participantes da comunicação regulam suas pertenças a grupos sociais e asseguram, assim, a solidariedade. E por personalidade entendo as competências que tornam um sujeito capaz de falar e de agir, isto é, de participar dos processos de entendimento e afrmar sua própria identidade 33 .

As noções de repertório, legitimidade e competência associam esses três níveis em um plano processual e não estrutural. É na própria dinâmica das interações comunicativas que o que pode ser aceito como conhecimento, o que é reconhecido como legítimo e quem pode falar ganham visibilidade e se materializam sob a forma de "fatos".

Se, como propôs Weber, o processo histórico de racionalização do mundo produziu a disjunção das esferas ${ }^{34}$, para Habermas, a linguagem ocupa hoje na produção dos consensos o lugar antes garantido pelo mito. Assim, contrariamente ao que pretendia Weber com sua noção de empatia, compreender a ação na perspectiva proposta por Habermas estaria vinculado à capacidade do pesquisador de descrever as ações em seus termos lingüísticos, ou seja, o modo como a linguagem comum codifica a percepção do mundo e suas normas.

Embora seu modelo da evolução social das sociedades modernas suponha o afastamento das narrativas míticas do plano da esfera de validade, em seu artigo de 200635 , Habermas reconhece que a religião ainda oferece uma base cognitiva importante ao mundo da vida cotidiana. Assim, como parte do mundo vivido ele propõe que ela seja analisada como componente da linguagem comum acionada nos contextos de interação. É certo que, se estes contextos visam à comunicabilidade, também as narrativas religiosas devem necessariamente produzir e apoiar-se em procedimentos compartilhados. Segundo Habermas, a reflexibilidade é uma das características mais importan-
[32] Araújo,op.cit.,p.161.

[33] Habermas, Théorie de l'agir communicationnel, op. cit., pp.151-52 (grifos nossos).

[34] Retomando a idéia de Weber ("A psicologia social das religiões mundiais". In: Ensaios de sociologia. 5 ed. Rio de Janeiro: Guanabara, 1979 [1913]) de secularização como separação das esferas de economia, política, religião, filosofia, estética e erótica, Habermas propõe no primeiro plano a separação entre mundo da vida $e$ sistema, e no interior delas a disjunção cultura, sociedade e personalidade, de um lado, estratificação, organização estatal e direito, de outro.

[35] Habermas. "Religion and the public sphere", op.cit. 
[36] Eley, Geoff. "Nations, publics, and political cultures: placing Habermas in the Nineteenth century". In: Calhoun (org.), op. cit., 1996, p.306.

[37] Habermas. "Religion and the public sphere", op. cit., pp. 6-13. tes desse tipo de interação. Desse modo, todas as certezas religiosas estão, como quaisquer outras, cada vez mais expostas à exigência de "ver de fora a sua fé", isto é, ser capaz de objetivá-la e de relacioná-la com outros pontos de vista.

É nesse ponto que o conceito de mundo da vida se encontra em Habermas com a noção de publicidade. A categoria de publicidade, central na obra habermasiana, permitiu-lhe articular a noção weberiana de racionalização com a noção política de legitimação. No contexto de seu trabalho de 1962, a constituição da esfera pública estava historicamente associada tanto à contraposição com o absolutismo e com a autoridade tradicional, como ao bloqueio à ascensão das classes subordinadas. O abandono da idéia de instituições de publicidade, no entanto, tais como salões, museus, jornais, igrejas, pela idéia de fluxo subtrai a base de uma investigação empírica que quer compreender por que apenas alguns sentidos fazem sentido. Do ponto de vista do fazer antropológico, não basta afirmar que os discursos religiosos ainda são capazes de produzirem sentidos: é preciso explicar por que algumas categorias religiosas funcionam melhor do que outras para estabelecer esses sentidos, por que algumas instituições religiosas são mais capazes do que outras de produzir proposições verossímeis a esse respeito. A nosso ver, se um conjunto amplo e variado de sentidos está disponível em determinado momento, nem todos vingam porque nem todos são percebidos como legítimos. Ora, os processos de produção de legitimidade que tomam forma no plano das mediações lingüísticas dependem, como dissemos anteriormente, da publicidade para estabilizar, ainda que provisoriamente, consensos a respeito dos sentidos das coisas e das intenções. O conceito de esfera pública teria assim melhor rendimento se for tomado como o locus onde controvérsias e negociações culturais entre uma variedade de públicos têm lugar ${ }^{36}$.

Ao tornar o princípio de publicidade condição da democracia, a esfera pública constitui-se para Habermas como espaço abstrato e virtual da crítica pública. É nesse sentido que as religiões também fazem parte do processo. Habermas reconhece que as religiões podem introduzir seus argumentos no debate público e ganhar adesão legítima a suas proposições. Não é problema para Habermas se o homem comum expressa suas convicções em linguagem ou argumentos religiosos. Do ponto de vista do sistema político, o que importa para Habermas são as afirmações e as questões que conseguem motivar cognitivamente as decisões e ganhar visibilidade no fluxo impessoal da comunicação pública 37 .

O autor reconhece, pois, que religião dá à vida cotidiana sua base cognitiva, e muitas das decisões individuais são tomadas a partir dela. Flexibilizando suas posições anteriores, o autor aceita neste artigo de 2006 que, por razões de ordem funcional, não se pode 
reduzir a polifonia das vozes públicas. Para ele, o conflito entre doutrinas e culturas que disputam a explicação da posição do homem no mundo não pode ser resolvido no plano normativo ou filosófico. Se as atitudes epistêmicas são expressão de um modo particular de ver o mundo, é apenas no plano do direito que se pode produzir a reciprocidade de expectativas. Essa ênfase no procedimento ameniza em parte a insatisfação de seus críticos com o que foi percebido como uma idealização do discurso racional na formação da esfera pública ${ }^{3}$. Embora, com efeito, a noção de esfera pública - que supõe a produção legítima da autoridade dos discursos - possa ser criticada pelos supostos de homogeneidade e univocidade que lhe são implícitos, a introdução do tema da religião e a aceitação da linguagem religiosa no debate tornam a disputa mais importante para a validade do procedimento, do que a qualidade dos discursos.

Se o princípio de publicidade é a regra magna do jogo da produção de legitimidades como sugere Lavalle39, há, no entanto, um limite para Habermas nesse exercício das razões polifônicas. Entre a "vida selvagem" da esfera pública e os procedimentos formais dos corpos políticos há, para o autor, uma demarcação institucional, "filtros das vozes de Babel no fluxo da comunicação pública que só deixam passar contribuições seculares" 40 . Ainda assim, a força das falas religiosas continuará a exercer seu direito de linguagem persuasiva na esfera pública enquanto outras linguagens mais convincentes para expressar um certo tipo de experiência não forem convencionadas. O que se requer é o exercício da reflexibilidade que põe em perspectiva uma fé com relação a outros pontos de vista - atitude epistêmica inerente ao agir comunicativo que tem como suposto a independência de uma religião com relação a outras, e destas em relação ao secular, cujas razões têm prioridade na arena propriamente política ${ }^{41}$. Assim, embora Habermas exclua a ação comunicativa do campo da política, confinando-a ao mundo sistêmico governado pela ação instrumental, ao retermos o "princípio de visibilidade" como noção-chave é possível tornar mais abrangente o próprio conceito de política, de modo a incluir as disputas simbólicas regidas pelos discursos. Do ponto de vista das relações políticas concebidas desse modo mais compreensivo, o que podemos reter como um avanço significativo do modelo habermasiano é a articulação que ele propõe entre a dimensão cognitiva e motivacional do mundo religioso já bem conhecida pela tradição dos estudos antropológicos - e os processos discursivos de produção de visibilidade no fluxo impessoal da comunicação pública. Posto que intangíveis, é preciso que a observação antropológica se dê os meios para descrever esses momentos fugazes e pouco sistemáticos nos quais "a formação da opinião emerge do mundo da vida e vem à luz pública" 42 .

[42] Lavalle, op. cit., p. 80.

[40] Habermas. "Religion and the public sphere", op. cit., p. 10 .

[41] Ibidem, p. 14 . 
Recebido para publicação

em 21 de janeiro de 2009 .

\section{NOVOS ESTUDOS}

CEBRAP

84 , julho 2009

pp. 199-213
A releitura da noção de esfera pública elaborada em sua obra de 1962 nos permite constituir como novos objetos de análise antropológica, não mais a objetivação de identidades, culturas e crenças religiosas pré-construídas que pleiteiam seus direitos (naturais) no espaço político, mas sim os fluxos comunicativos oriundos do mundo da vida e seu modo de constituir discursivamente identidades, tradições e crenças. Na esfera pública as controvérsias e as negociações culturais entre uma variedade de públicos em torno da validade de certas proposições têm lugar e se tornam visíveis. Ao trazer os processos de reflexibilidade para o foco de sua atenção, a antropologia poderá contribuir para lançar uma nova luz sobre as modalidades de consentimento de cujo funcionamento deriva toda atividade política.

PAULA MONTERO é professora titular do Departamento de Antropologia da USP e pesquisadora do Cebrap. 